\title{
Effect of intermittent left anterior hemiblock on left ventricular function
}

\author{
R. H. Swanton, D. J. Coltart, B. S. Jenkins, and M. M. Webb-Peploe \\ From the Department of Cardiology, St. Thomas' Hospital, London
}

Studies of left ventricular function were performed during intermittent left anterior hemiblock. Max dP/dt and $V_{\max }$ fell during left anterior hemiblock, with a rise in left ventricular end-diastolic pressure compared with a normally conducted beat.

The haemodynamic consequences of cardiac arrhythmias are determined by the nature of the arrhythmias and by the intrinsic state of the myocardium. Impairment of cardiac performance during an arrhythmia in comparison with normal sinus rhythm may be caused by loss of atrial transport or asynchronous ventricular contraction. This paper reports the haemodynamic effect of left anterior hemiblock in a patient with coronary artery disease and aortic regurgitation secondary to syphilis.

\section{Case report}

A 56-year-old male interior decorator was admitted to hospital with a history of retrosternal chest pain. On examination he was found to have aortic regurgitation but no clinical or electrocardiographic evidence of an aortic aneurysm or myocardial infarction. Tests for syphilis were positive in blood, but negative in cerebrospinal fluid. He was treated with penicillin. Six years later he was readmitted to hospital with one month's history of increasing exertional dyspnoea, paroxysmal nocturnal dyspnoea, and angina. On examination he was in regular rhythm with a collapsing pulse. Blood pressure $120 / 60 \mathrm{mmHg}$. Jugular venous pressure normal. On palpation he had left ventricular hypertrophy and the auscultatory signs of aortic regurgitation. No clinical signs of tabes dorsalis were elicited. All routine investigations, including blood cultures, were normal apart from a positive Wassermann reaction, positive VDRL slide test, and positive fluorescent treponemal antibody absorption test. Electrocardiogram showed sinus rhythm, PR interval $0.18 \mathrm{sec}$, mean frontal $Q R S$ vector $0^{\circ}$, and an old anteroseptal myocardial infarct. Chest $x$-ray showed an enlarged heart with a normal aortic knuckle and no aortic valve calcification. Kerley B lines were present.

Cardiac catheterization demonstrated impaired left ventricular function and aortic regurgitation with diffuse coronary artery disease.

\section{Cardiac catheterization}

Pressures were measured using Statham P23 Gb transducers and a Cambridge 12-channel recorder.

Left ventricular function studies were performed using a Telco catheter-tip micromanometer (MM 52) with a linear frequency response to $\mathrm{I} \mathrm{kHz}$. The pressure was processed through a differentiator using a Thompson low pass filter. Force-velocity loops from left ventricular pressures were derived (Grossman et al., 1971). The logarithm of developed pressure was differentiated to give $\mathrm{dP} / \mathrm{dt}$ divided by developed pressure. This was displayed on the vertical axis of the XY oscilloscope of the Cambridge recorder and left ventricular pressure on the horizontal axis. From the force-velocity loop logarithmic values of $\mathrm{dP} / \mathrm{dt}$ divided by developed pressure were plotted against the linear values of the left ventricular pressure. The resultant isovolumic fraction of this plot was extrapolated to left ventricular end-diastolic pressure generating $\mathrm{kV}_{\max }$. Cardiac output was taken as the mean of three estimations from indocyanine green dye dilution curves. Angiographic volume data were obtained using the single plane area length method.

\section{Results}

The results of cardiac catheterization are shown in Table $\mathrm{I}$. The haemodynamic change during a period of left anterior hemiblock is shown in Table 2. The reduction in $\max \mathrm{dP} / \mathrm{dt}$ with the onset of left anterior hemiblock is statistically significant $(\mathbf{P}<$ 0.01 ). The $R R$ intervals and PR intervals were identical. Peak left ventricular systolic pressure did not change with the alteration of conduction (Fig. I). Post-ectopic beats showed an increase in left ven- 
TABLE I Catheter data in normal conduction

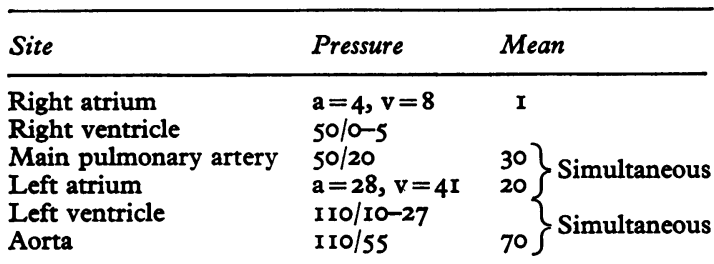

Cardiac output $=2.71 . / \mathrm{min}$

Cardiac index $=1.51 . / \mathrm{min}$ per $\mathrm{m}^{2}$

Pulmonary vascular resistance $=3.7$ units

Systemic vascular resistance $=25.6$ units

\begin{tabular}{lc}
\hline Angiographic volume data & Normal ${ }^{\star}$ \\
\hline End-diastolic volume index $=197 \mathrm{ml} / \mathrm{m}^{2}$ & $70 \pm 17 \mathrm{ml} / \mathrm{m}^{2}$ \\
End-systolic volume index $=157 \mathrm{ml} / \mathrm{m}^{2}$ & $21 \pm 7 \mathrm{ml} / \mathrm{m}^{2}$ \\
Stroke volume index $=39 \mathrm{ml} / \mathrm{m}^{2}$ & $49 \pm 10 \mathrm{ml} / \mathrm{m}^{2}$ \\
Ejection fraction $=0.2$ & $0.7 \pm 0.03$ \\
Normalized ejection rate $=\mathrm{I} \cdot \mathrm{I} \mathrm{vol} / \mathrm{sec}$ & $3.24 \pm 0.86 \mathrm{vol} / \mathrm{sec}$
\end{tabular}

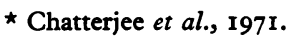

tricular pressure with a significant rise in $\max \mathrm{dP} / \mathrm{dt}$ and $V_{\max }(P<0.0 I)$. Left ventricular alternans occurred after ectopic beats. This pattern of re-
TABLE 2 Left ventricular function with change of conduction

\begin{tabular}{|c|c|c|c|}
\hline & $\begin{array}{l}\text { Normal } \\
\text { conduction }\end{array}$ & $\begin{array}{l}\text { Left } \\
\text { anterior } \\
\text { hemiblock }\end{array}$ & $\begin{array}{l}\text { Post- } \\
\text { ectopic } \\
\text { beat }\end{array}$ \\
\hline $\begin{array}{l}\text { Aortic pressure (mmHg) } \\
\text { Left ventricular end- } \\
\text { diastolic pressure }\end{array}$ & $110 / 55$ & $110 / 55$ & $120 / 50$ \\
\hline $\begin{array}{c}(\mathrm{mmHg}) \\
\max \mathrm{dP} / \mathrm{dt}(\mathrm{mmHg} / \mathrm{sec})\end{array}$ & $\begin{array}{r}27 \\
850\end{array}$ & $\begin{array}{r}33 \\
740\end{array}$ & $\begin{array}{r}33 \\
960\end{array}$ \\
\hline $\begin{array}{l}\mathrm{kV}_{\max }\left(\mathrm{sec}^{-1}\right) \\
\mathrm{V}_{\max } \text { (muscle lengths/sec) } \\
\mathbf{R} R \text { interval (sec) }\end{array}$ & $\begin{array}{l}85 \\
2 \cdot 9 \\
0.83\end{array}$ & $\begin{array}{l}58 \\
2 \cdot 0 \\
0.83\end{array}$ & $\begin{array}{l}\text { II } 4 \\
\quad 4 \cdot 0 \\
I \cdot I\end{array}$ \\
\hline
\end{tabular}

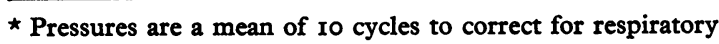
swing.

sponse indicates poor left ventricular function (Beck, Chesler, and Schrire, I97I). The force-velocity loops are shown in Fig. 2. Fig. 2a shows 5 successive loops: 3 during left anterior hemiblock and 2 in normal conduction. Fig. $2 \mathrm{~b}$ shows the loop of a postectopic beat. The semilogarithmic plot of the loops is shown in Fig. 2c. Assuming a coefficient of series elasticity (k) of $28.8 \mathrm{~cm}^{-1}$ (Falsetti et al., 197I),

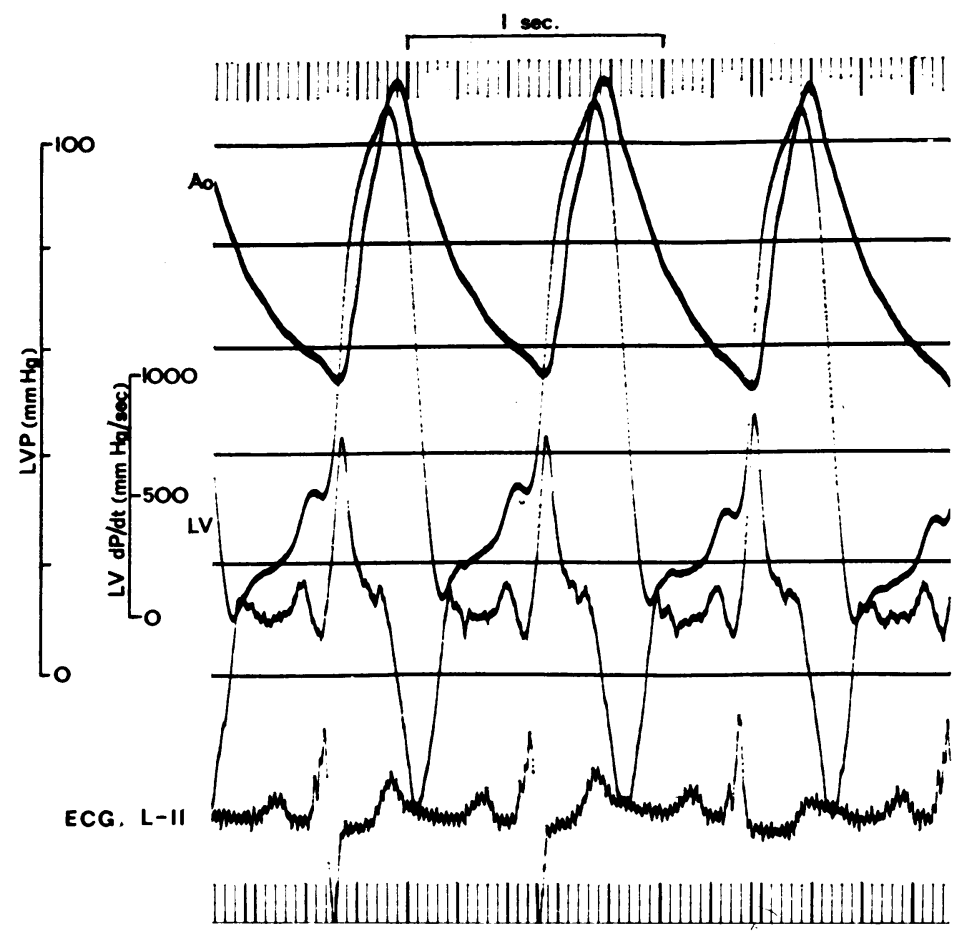

FIG. I The change from left anterior hemiblock to normal conduction produces a fall in left ventricular end-diastolic pressure (LVEDP) and a rise in max $d P / d t$. There is no change in peak left ventricular pressure, $R R$, or $P R$ intervals. 
a)

Normal and Left anterior hemiblock beats



(b)

Post-ectopic beat



FIG. 2 a) Five successive force-velocity loops. Three in left anterior hemiblock, two in normal conduction. b) Force-velocity loop of a post-ectopic beat. c) Semilogarithmic plot of the loops extrapolated to appropriate left ventricular end-diastolic pressure (LVEDP). 
$\mathrm{V}_{\max }$ was low (Graham et al., 197I) yet showed some post-ectopic augmentation. Angiographic volumes (Table I) confirmed poor left ventricular function with a large heart, low ejection fraction, and reduced normalized ejection rate. Aortic root cineangiography showed grade I aortic regurgitation. Selective coronary arteriography (Judkins method) showed diffuse narrowing of anterior descending and circumflex arteries, but a normal dominant right coronary artery.

\section{Discussion}

Interest in haemodynamic effects of abnormalities of cardiac conduction dates back many years. Wiggers (I925) first reported in the canine myocardium that anomalous ventricular depolarization resulted in reduced peak and rate of rise of left ventricular pressure. Isovolumic contraction phase and duration of systole were longer than control periods. Further experimental work by Gilmore et al. (1963) demonstrated a reduction in left ventricular stroke work and cardiac output by changing from atrial to ventricular epicardial pacing. During ventricular stimulation not only was the ventricle deprived of the atrial contribution to ventricular filling, but the rate of rise of left ventricular pressure was decreased because of asynchronous ventricular contraction. To dissociate these two factors Samet, Castillo, and Bernstein (I966) studied sequential atrioventricular pacing in man. It was shown that atrial contribution to ventricular filling was more important than aberrant ventricular depolarization. Gibson et al. (1971) studied changes in myocardial function during right ventricular, left ventricular, and biventricular pacing in patients after aortic valve replacement. On changing from single to biventricular pacing aortic pressure did not change while ball travel time was reduced. Ball travel time was also decreased by altering the epicardial pacing site from right to left ventricle. These results suggest that a change in left ventricular activation does not necessarily alter the external work done by the heart.

During right bundle-branch block it has been shown that there is a delay in onset of right ventricular contraction (Braunwald et al., I956) and a reduction in right ventricular contractility (Johnston et al., 1966), as judged by an increase in presystolic time intervals and a decrease in $\max \mathrm{dP} / \mathrm{dt}$.

Recently the effect of intermittent left bundlebranch block on left ventricular contractility has been reported in a single case (Takeshita, Basta, and Kioschos, 1974). The ratio of $\max \mathrm{dP} / \mathrm{dt}$ to peak developed pressure was reduced in left bundlebranch block, while the isovolumic contraction time was increased. However, Haft, Herman, and Gorlin
(1971) showed a normal isovolumic contraction time in patients with left bundle-branch block in the absence of underlying myocardial dysfunction.

In our case left anterior hemiblock caused a decrease in max dP/dt and a rise in left ventricular enddiastolic pressure. The RR intervals and PR intervals remained unchanged so that the fall in $\max \mathrm{dP} /$ dt cannot be attributed either to a change in heart rate or to a change in the time relations of atrial and ventricular contraction. Aortic pressure (and thus afterload) did not change. The decrease in $\max$ $\mathrm{dP} / \mathrm{dt}$ occurred in the face of an increase in left ventricular end-diastolic pressure. With heart rate and afterload constant and preload increasing, the fall in max dP/dt must be caused by a fall in contractility. This was substantiated by a fall in $V_{\max }$.

$\mathrm{V}_{\max }$ derived from pressure velocity curves has been reported to be a useful index of contractility as it is relatively independent of preload and afterload (Brutsaert and Sonnenblick, 1973). Current knowledge concerning muscle models suggests that developed pressure (as used in this study) rather than total pressure may be the more appropriate variable for use in force velocity calculations (Parmley and Sonnenblick, I970).

This case showed evidence of poor left ventricular function as measured by several parameters, and during left anterior hemiblock left ventricular contractility was impaired still further.

\section{References}

Beck, W., Chesler, E., and Schrire, V. (197r). Postextrasystolic ventricular pressure responses. Circulation, 44, 523.

Braunwald, E., Donoso, E., Sapin, S. O., and Grishman, A. (1956). Right bundle branch block. Hemodynamic, vectorcardiographic and electrocardiographic observations. Circulation, 13, 866.

Brutsaert, D. L., and Sonnenblick, E. H. (1973). Cardiac muscle mechanics in the evaluation of myocardial contractility and pump function: problems, concepts, and directions. Progress in Cardiovascular Diseases, 16, 337.

Chatterjee, K., Sacoor, M., Sutton, G. C., and Miller, G. A. H. (197I). Assessment of left ventricular function by single plane cineangiographic volume analysis. British Heart fournal, 33, 565.

Falsetti, H. L., Mates, R. E., Greene, D. G., and Bunnell, I. L. (1971). Vmax as an index of contractile state in man. Circulation, 43, 467.

Gibson, D. G., Chamberlain, D. A., Coltart, D. J., and Mercer, J. (1971). Effect of changes in ventricular activation on cardiac haemodynamics in man. British Heart Fournal, 33, 397.

Gilmore, J. P., Sarnoff, S. J., Mitchell, J. H., and Linden, R. J. (1963). Synchronicity of ventricular contraction: observations comparing haemodynamic effects of atrial and ventricular pacing. British Heart fournal, 25, 299.

Graham, T. P., Jr., Jarmakani, J. M., Canent, R. V., Jr., and Anderson, P. A. W. (197I). Evaluation of left ventricular contractile state in childhood: normal values and observations with a pressure overload. Circulation, 44, 1043. 
Grossman, W., Brooks, H, Meister, S., Sherman, H., and Dexter, L. (197I). New technique for determining instantaneous myocardial force-velocity relations in the intact heart. Circulation Research, 28, 290.

Haft, J. I., Herman, M. V., and Gorlin, R. (1971). Left bundle branch block. Etiologic, hemodynamic, and ventriculographic considerations. Circulation, 43, 279.

Johnston, R. R., Mullins, C. B., Gupta, D. N., and Mitchell, J. H. (I966). Effect of intermittent right bundle branch block on right ventricular contractility. American fournal of Cardiology, 17, 813.

Parmley, W. W., and Sonnenblick, E. H. (1970). Re-evaluation of Vmax as an index of contractile state: an analysis of different muscle models (abstract). Circulation, 42, Suppl. 3, II5.
Samet, P., Castillo, C., and Bernstein, W. H. (I966). Haemodynamic sequelae of atrial, ventricular, and sequential atrioventricular pacing in cardiac patients. American Heart Fournal, 72, 725 .

Takeshita, A., Basta, L. L., and Kioschos, J. M. (1974). Effect of intermittent left bundle branch block on left ventricular performance. American fournal of Medicine, 56, 251.

Wiggers, C. J. (1925). The muscular reactions of the mammalian ventricles to artificial surface stimuli. American fournal of Physiology, 73, 346.

Requests for reprints to Dr. R. H. Swanton, Department of Cardiology, St. Thomas' Hospital, London SEr $7 \mathrm{EH}$. 